\title{
OUR EXPERIENCE OF 400 COCHLEAR IMPLANTS IN THE STATE OF UP
}

Authors:

Rohit Mehrotra', Anubhaw ${ }^{2}$, Pankaj Srivastav $^{3}$, Rudresh Sharma ${ }^{4}$, Ujjwal Mehrotra $^{5}$

Authors Affiliations:

(1) Consultant (Prof.)(2) Consultant (3) Consultant (4) Audiologist (5) Student MBBS $3^{\text {rd }}$ yr. ENT Specialists, Mehrotra ENT Hospital, Ashok Nagar, Kanpur, U.P., India

\section{ABSTRACT}

IIntroduction : This retrospective study is based on experience of 400 cochlear implantation at late Dr S N Mehrotra Charitable ENT foundation between 2016 to 2019. Materials and Methods: 400 children who were implanted between 2016-2019 in Mehrotra ENT Hospital were included in the study. Outcomes of all the implanted children were analyzed. Scoring system for auditory performance(REVISED CAP), speech rehabilitation(SIR) and quality of life(GCBI) were also taken into account for every child implanted taking into consideration practical issues in Indian set up. Results: Majority of children(54.25\%) were in age group 3-5 years. All were pre lingual deaf children. $53.25 \%$ were implanted with $\mathrm{Cl} 24 \mathrm{RE}$ (ST) from Nucleus and rest with Digisonic SP. 92\% were implanted through posterior tympanotomy. $89.8 \%$ had round window insertion and $10.2 \%$ cochleostomy. $83.3 \%$ were in regular follow up. $25(6.25 \%)$ had abnormal cochlea. Complications were few and managed successfully. More than $90 \%$ had improvement in hearing and quality of life. Conclusion: Outcome in terms of auditory perception, speech and quality of life was excellent taking into considerations practical issues in Indian setup. Early age implantation, regular follow up, extensive rehabilitation, prior hearing aid users and presence of residual hearing are good prognostic factors in our experience of 400 cochlear implants.
Complications being minimal and manageable, surgery was safe.

\section{Keywords}

Cochlear implantation, abnormal cochlea, REVISED CAP, SIR, GCBI.

\section{INTRODUCTION}

Over the last few years cochlear implantation has become the important treatment modality for children with severe to profound sensory neural hearing loss ${ }^{[1,2,3,4]}$. Inspite of dramatic improvement in cochlear implantation, various other factors decide the final result and outcome of implantation ${ }^{[5]}$.

Variables affecting outcome of implant ${ }^{[6,7]}$ are duration of disease, etiology of disease, age at onset of deafness, pre implant hearing aid use, communication mode, age at implantation ${ }^{[4]}$, type of speech processor, duration of implant usage, family support and financial status, expertise provided, facilities for rehabilitation.

Problems unique to Indian scenarios of multi lingual society is of language barrier for rehabilitation. Well equipped audiology unit with expertise team of audiologist are the basics for rehabilitation. Access to good schools for hearing challenged is the future way for good rehabilitation. Uniform rehabilitation in their mother tongue with active child's parent participation are essentials for auditory verbal 
rehabilitation[8].

Developing habilitation methods in various regional languages is a daunting tasks for diverse Indian culture. Yet cochlear implantation program has grown exponentially.

The cochlear implantation program at Late Dr. S N Mehrotra Charitable ENT Foundation, KANPUR lays emphasis on after care and the extensive rehabilitation with a dedicated team of ENT surgeons, Audiologist, speech therapist, auditory verbal habilitationist and other staffs under one roof.

\section{MATERIALS AND METHODS}

Study was carried out at late Dr S N Mehrotra Charitable ENT foundation from 2016 to 2019. 400 children implanted during this period were taken into consideration. Study was done by collecting data through fully completed clinical records and information regarding present performance of implantees from our team. The discussion also includes feedback from rehabilitation team about performance of each implantee, the duration at which patients attained speech abilities and reach the respective categories of Categories of auditory performance (REVISED CAP) and speech intelligibility rating (SIR) score and their Glasgow Children Benefit Inventory (GCBI) index.

The following inclusion were applied to all the selected subjects in the study.

\section{Inclusion criteria}

a) Children with bilateral severe to profound sensori-neural hearing loss.

b) Had hearing aid trial for minimum of 3 months

c) Psychological assessment was normal.

\section{Evaluation protocol at MEHROTRA ENT HOSPITAL}

a. Informed written consent was taken from the parents for the study and follow-ups required during the study. b. A detailed history and thorough physical and ENT examination was carried out.

c. The subjects then underwent pediatric examination to rule out any neurological condition, which may hamper the child postoperative performance. Prior to implantation a basic workup including hematological, chest X-ray, ECG (electrocardiogram), TORCH (toxoplasmosis, rubella, cytomegalovirus, herpes simplex, and HIV) screen (if require). The general physical condition will be evaluated by anaesthetist. A specialist opinion was sought in patients with syndromic etiology of deafness. In children pneumococcal vaccination will be carried out.

d. Behavioral observational audiometry, impedance, OAE(otoacoustic emissions), auditory brainstem response thresholds and auditory steady-state response was determind to evaluate the degree of hearing loss in all cases.

e. Each child was subjected to undergo a high resolution $\mathrm{CT}$ (computed tomography) scan and MRI (magnetic resonance imaging)scan of Temporal bones to assess mastoid and cochlea.

f. Speech intelligibility was also assessed by SIR score before implant

g. The child was also evaluated by a child psychologist to determine the IQ(intelligent quotient).

h. Counseling of parents was done by speech therapist regarding regular follow-ups and therapy/support to the child at home. They were also made to realize the realistic expectations about the cochlear implant. Also the parents were made to realize that they are integral part of our rehabilitation team which requires consistent hard work and patience.

Cochlear implantation was done and the impedance checked. NEURAL RESPONSE TELEMETRY (NRT) was done in nucleus implants and effectiveness assessed in children. Post operatively $\mathrm{x}$ ray was mandatory.

The switch on and speech processor tuning done at 1-2 weeks after surgery. Mapping is done at 
periodic intervals till a stable map is achieved. The rehabilitation program was started out based on baseline skills of child, periodical assessment of outcomes was done in terms of environmental sound speech discrimination and telephonic conversation. The recommended period for rehabilitation is 2 years. All 400 children are using the implant. There are no non users.

\section{OUTCOME MEASURES}

The subjects were followed up for a maximum period of 1 year at intervals of 3 months, 6 months and 12 months after implantation. Outcome measures were followed as under CAP SCORE, SIR score and GCBI index ${ }^{[9,10,11]}$

\section{RESULTS}

TABLE 1: AGE GROUP DISTRIBUTION

\begin{tabular}{|l|l|}
\hline AGE GROUPS & NUMBER OF CHILDREN \\
\hline Less than 1 year & 10 \\
\hline 1-2 years & 41 \\
\hline 2-3 years & 70 \\
\hline 3-4 year & 108 \\
\hline 4-5 year & 109 \\
\hline 5-6 years & 56 \\
\hline 6-10 years & 06 \\
\hline
\end{tabular}

- Out of total 400 children 212 were males and 188 were females.299 were Hindu and 101 muslim.

- 151 were general category, 192 other backward class and 57 SC category.

- 160 children are of Kanpur nagar, 240 of other districts

- All children were prelingual deaf.

- 3 children died in follow up period. 1 died in road traffic accident, 1 died due to dengue fever and 1 due to viral encephalitis. All were unrelated to surgery.

- $310(77.5 \%)$ children were operated in right side and $90(22.5 \%)$ in left side.

- $213(53.25 \%)$ children were implanted with freedom device and 187(46.75\%) with digisonic
- $97.8 \%$ had full insertion whereas $2.1 \%$ had 2-5 electrodes outside

- 368 children(92\%) were implanted through posterior tympanotomy and 32(8\%) were implanted through varia technique.

- 25 patients $(6.25 \%)$ patients had abnormal cochlea.

TABLE 2 : ABNORMAL COCHLEA FINDINGS

\begin{tabular}{|l|l|}
\hline ABNORMAL COCHLEA FINDINGS & NUMBER OF CHILDREN \\
\hline Common cavity & 01 \\
\hline $\mathrm{IP}_{1}$ & 04 \\
\hline $\mathrm{IP}_{2}$ & 15 \\
\hline $\mathrm{IP}_{3}$ & 02 \\
\hline Ossified cochlea & 03 \\
\hline
\end{tabular}

- Wearing hearing aid early helped the children to improve auditory skills

- $11.1 \%$ children used hearing aids $<4$ months

- $24.4 \%$ children used hearing aids $4-6$ months

- $10.8 \%$ children used hearing aids 6-8 months

- $53.6 \%$ children used hearing aids $>8$ months

- $89.8 \%$ had round window insertion and $10.2 \%$ cochleostomy.

\section{COMPARISON OF SIR SCORE, GCBI AND CAP SCORE}

TABLE 3 : CAP SCORE AT END OF 1 YEAR

\begin{tabular}{|l|l|}
\hline LEVELS & $\begin{array}{l}\text { AT THE END OF 12 } \\
\text { MONTHS }\end{array}$ \\
\hline 11 & $02 \%$ \\
\hline 10 & $04 \%$ \\
\hline 09 & $07 \%$ \\
\hline 08 & $08 \%$ \\
\hline 07 & $18 \%$ \\
\hline 06 & $21 \%$ \\
\hline 05 & $25 \%$ \\
\hline 04 & $13 \%$ \\
\hline 03 & $02 \%$ \\
\hline
\end{tabular}


TABLE 4: SIR AT END OF 1 YEAR

\begin{tabular}{|l|l|}
\hline CATEGORY OF SIR & PERCENTAGE OF CHILDREN \\
\hline 05 & $16 \%$ \\
\hline 04 & $34 \%$ \\
\hline 03 & $30 \%$ \\
\hline 02 & $19 \%$ \\
\hline 01 & $01 \%$ \\
\hline
\end{tabular}

TABLE 5 : GCBI AT END OF 1 YEAR

\begin{tabular}{|l|l|}
\hline INDEX & PERCENTAGE \\
\hline $60-100$ & $64 \%$ \\
\hline $30-60$ & $26 \%$ \\
\hline $0-30$ & $10 \%$ \\
\hline
\end{tabular}

Overall outcome in terms of REVISED CAP, SIR and GCBI was very good. $90 \%$ showed significant improvement in hearing, $80 \%$ with speech and $90 \%$ with improved quality of life.

One year is a relatively short follow up period for evaluation of outcome. Communication skills continue to improve for several years post implantation ${ }^{[11,12]}$ and hence present results reflect only short term outcome. However most children achieved higher scores for both CAP and SIR after one year postoperatively, probably indicating that in future they will master communication skills at higher level ${ }^{[13,14],}$ the results of which will be available further publications.

\section{- FOLLOWUP}

$83.30 \%$ children were regular in follow up. $16.60 \%$ irregular.

\section{COMPLICATIONS}

Complications were more related to abnormal anatomy rather than related to surgical procedure.
- 5 children developed CSF gusher /leak during operation which was managed successfully

- 07 patients had facial paresis which recovered in 4-6 weeks

- 12 children had hematoma. 1was aspirated and recovered. Rest recovered conservatively in 2 weeks.

- 05 had discharge from operated ear which recovered in 01 week

- 01 keloid which was excised later.

- 1 had device failure which was replaced.

\section{CONCLUSION}

- Early age ${ }^{[15]}$ of less than 3 years or ideally less than 2 years showed better hearing, better speech and better quality of life. Spoken language performance results are best for those implanted prior to age 3 .

- Religion plays no role.

- Prior hearing aid users performed better in all aspects. The greater the period of hearing aid use and shorter the period of time of hearing deprivation ${ }^{[4,16]}$ better the outcome and easier development of spoken language.

- Regular follow up during rehabilitation is key to improve results

- Dedicated educated parents are as important as other factors for successful outcome.

- As the complications were minimal, surgery was safe ${ }^{[17]}$. Most of them related to abnormal cochlea.

- All children were using the implant. There were no non users.

- Nearly $90 \%$ children hearing improved, speech in $80 \%$ and overall quality of life in $80 \%$ of children implanted. 


\section{BIBLIOGRAPHY}

1. Beadle EAR, McKinley DJ, Nikolopoulos TP (2005) Long-term functional outcomes and academic-occupational status in implanted children after 10 to 14 years of cochlear implant use. Otol Neurotol 26:1152-1160.

2. Hehar SS, Nikolopoulos TP (2002) Surgery and functional outcomes in deaf children receiving cochlear implants before age 2 years. Arch Otolaryngol Head Neck Surg 128:11-14.

3. NICE technology appraisal guidance TAG166 (2009) Cochlear implants for children and adults with severe to profound deafness

4. O'Neil C, O' Donoghue GM, Archbold SM (2001) Variations in gains in auditory performance from pediatric cochlear implantation. Otol Ncurotol 23:44-48.

5. Colleti, Vittorio MD, Carner, Marco MD, Miorelli, Veronica, Cochlear implantation at under 12 months; Report on 10 Patients. Laryngoscope 2005; Page no 115:445

6. Black J, Hickson L, Black B (2012) Defining and evaluating success in paediatric cochlear implantation-an exploratory study. Int J Pediatr Otorhinolaryngol 76: 1317-1326.

7. Driver S, Jiang D (2017) Paediatric cochlear implantation factors that affect outcomes. Eur J Paediatr Neurol 21:104-108.

8. Tait M, Lutman ME. Predictive value of measures of preverbal communicative behavior in young deaf children with cochlear implants. Ear Hearing 1997; 8:472-8.

9. Archbold $\mathrm{S}$, Lutman $\mathrm{ME}$, Marshall $\mathrm{DH}$. Categories of Auditory Performance(Ann Otol Rhinol Laryngol, 1995: page no. 166:312)

10.Allen C, Nikolopoulos TP, Dyar D (2001) Reliability of a rating scale for measuring speech intelligibility after paediatric cochlear implantation. Otol Neurotol 22:631-633.

11. Allen C, Nikolopoulos TP, O'Donoghue GM (1998) Speech intelligibility after cochlear implantation. Am J Otol 19: 742-746.

12. Nikolopoulos TP, Archbold SM, O'Donoghue
GM (1999) The development of auditory perception in children following cochlear implantation. Int J Pediatr Otorhinolaryngol 49: S189-S191.

13. Calmels MN, Saliba I, Wanna G (2004) Speech perception and speech intelligibility in children after cochlear implantation. Int J Pediatr Otorhinolaryngol 68:347-351.

14. Inscoe J (1999) Communication outcomes after paediatric cochlear implantation. Int J Pediatr Otorhinolaryngol 47: 195-200

15. Osberger MJ, Cochlear Implantation in children under 2 years, Candidacy consideration, Otolaryngol Head Neck Surg 1997;117:145-8

16. Waltzman SB, Roland JT Jr, Cohen NL (2002) Delayed implantation in congenitally deaf children and adults. Otol Neurotol 23:333-340.

17. Ovesen T, Johansen LV (2009) Post-operative problems and complications in 313 consecutive cochlear implantations. J Laryngol Otol 123: 492496.

\section{Declarations}

Compliance with Ethical Standards

Disclosure of potential conflicts of interest : None Research involving human participants and/or animals: No Informed consent: Yes

\section{Corresponding Author:}

Dr. (Prof.) Rohit Mehrotra

Consultant ENTSpecialist

Director- Mehrotra ENT Hospital, Ashok Nagar, Kanpur, U.P., India

E-mail:mehrotraent@rediffmail.com

\section{How to Cite this Article:}

Rohit Mehrotra, Anubhaw, Pankaj Srivastav, Rudresh Sharma, Ujjwal Mehrotra - Our Experience of 400 Cochlear Implants in the State of UP - UP State Journal of Otolaryngology and Head and Neck Surgery Volume-8/Special edition/page 22-26

https://doi.org/10.36611/upjohns/se/2020/1 